\title{
Sustentabilidade socioambiental e a retórica neodesenvolvimentista: apontamentos sobre meio ambiente e saúde no Brasil
}

\section{Socio environmental sustainability and the neodevelopmentalist rethoric: notes on environment and health in Brazil}

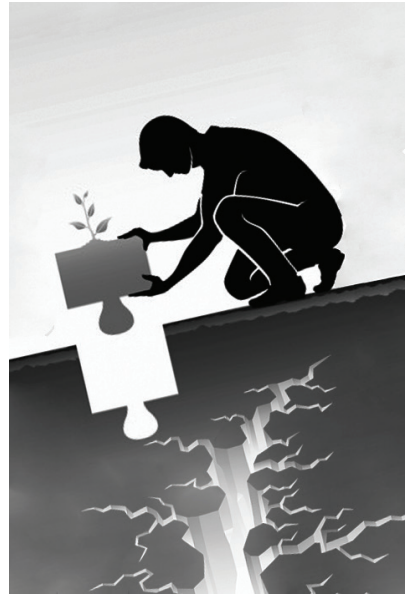

\section{Maria das Graças e Silva*}

Professora doutora do Departamento de Serviço Social da Universidade Federal de Pernambuco (UFPE) Recife/PE, Brasil.

Resumo: O objetivo deste artigo é problematizar as principais contradições do modelo de desenvolvimento brasileiro, o "neodesenvolvimentismo", enfocando a relação ambiente/saúde e suas principais manifestações no contexto atual. Advoga-se que em nome da sustentabilidade econômica promove-se uma insustentabilidade socioambiental, com fortes rebatimentos sobre a saúde da população. Pretende-se desvelar as contradições que se põem na atual conjuntura e a ideologia que lhe dá suporte, a qual manifesta o próprio modo de ser burguês.

Palavras-chave: Neodesenvolvimentismo. Meio ambiente. Saúde.

\begin{abstract}
This article aims at questioning the main contradictions of the Brazilian developmental model, the "neodevelopmentalism", and it does so by focusing the relationship between environment and health, and its main expressions in the current context. It is said that on behalf of economic sustainability, a socio environmental unsustainability is promoted, and it spreads over the population's health. We intend to unveil the contradictions of the current situation and its supporting ideology, which expresses the bourgeois way of being itself.
\end{abstract}

Keywords: Neodevelopmentalism. Environment. Health.

\footnotetext{
*E-mail: gracita.pe@gmail.com.
} 


\section{Introdução}

A

s preocupações em torno da problemática ambiental e suas repercussões na saúde humana integram os estudos na área de saúde pública desde seus primórdios, embora só a partir da segunda metade do século XX tenham se constatado os maiores avanços no trato dessas interconexões.

$\mathrm{O}$ aprofundamento da destrutividade ambiental planetária tem revelado que as questões atinentes à saúde humana só podem ser efetivamente apreendidas em sua estreita relação com o ambiente, posto que a ofensiva do capital sobre os recursos ecossistêmicos tem impactado cada vez mais intensamente as condições e o modo de vida das populações, especialmente dos seus segmentos mais pauperizados. Este contexto impõe aos pesquisadores, estudiosos, gestores e aos movimentos sociais o desafio de apreender os processos de degradação ambiental — bem como sua relação com a saúde da população - em sua estreita relação com os determinantes socioeconômicos que lhes são subjacentes.

No Brasil, o tratamento da temática ambiental em sua articulação com os processos de adoecimento vem se alargando como objeto de estudos e pesquisas, incorporando, mais recentemente, as múltiplas formas de discriminação — étnico-racial, gênero, raça, classe, dentre outros - que atingem amplos segmentos da sociedade. A ampliação desse campo de estudos se deu especialmente a partir dos anos 2000, resgatando e atualizando uma tradição no campo das ciências sociais e da medicina social no enfrentamento das desigualdades e da luta por democracia, expansão essa fortemente influenciada pela noção de justiça ambiental ${ }^{1}$ (Porto, Pacheco e Leroy, 2013). ${ }^{2}$

Os avanços nesse campo remetem-se às conquistas obtidas em longo processo histórico de lutas e resistências, capitaneadas pelo movimento da reforma sanitária, culminando com o redimensionamento do conceito de saúde. Ao paradigma

1. "Justiça ambiental se refere ao tratamento justo e ao envolvimento pleno de todos os grupos sociais, independente de sua origem ou renda, nas decisões sobre o acesso, ocupação e uso dos recursos naturais em seus territórios" (Rede Brasileira de Justiça Ambiental — Declaração de Princípios). Disponível em: < http:// www.justicaambiental.org.br/_justicaambiental/pagina.php?id=229>. Acesso em: 10 maio 2012.

2. Os autores afirmam ainda que o engajamento dos pesquisadores envolvidos com a temática, muitos deles ativistas dos movimentos de direitos humanos ou membros das comunidades afetadas, traz uma proposta de uma "ciência ativista" ou "ciência cidadã". 
hospitalo-cêntrico e à mercantilização da saúde se contrapunha um modelo centrado na prevenção e na universalização do acesso, "garantido mediante políticas sociais e econômicas que visem à redução do risco de doença [...], [contemplando] a sua promoção, proteção e recuperação". ${ }^{3}$ Com isso, ampliou-se a consciência de que a saúde, individual e coletiva, está intrinsecamente relacionada à qualidade do meio ambiente (Ribeiro, 2004). Essa relação vem se tornando inequívoca nas últimas décadas, em razão do modelo de desenvolvimento em curso no país, caucionado em grandes projetos voltados para a expansão do capital no território nacional, com forte apoio do aparato estatal e uso intensivo de recursos naturais.

$\mathrm{O}$ aprofundamento do processo de mercantilização da natureza, através da biopirataria, da grilagem, da pilhagem dos recursos naturais e a instauração dos grandes empreendimentos e atividades poluidoras em geral, tem produzido impactos sobre a saúde e o modo de vida das populações atingidas, especialmente os denominados povos ou comunidades tradicionais, acentuando-se, assim, os conflitos socioambientais. ${ }^{4}$

A tarefa de apreender esses fenômenos supõe e exige um esforço de problematizar os nexos entre saúde e ambiente a partir do contexto sócio-histórico que lhe funda, posto que tanto a degradação ambiental quanto as questões afetas à saúde guardam, mediata ou imediatamente, relação com a acumulação capitalista e o atual padrão de desenvolvimento que a impulsiona.

O desafio consiste em romper com as concepções reducionistas e fragmentadas no trato da temática. As correntes advindas da ecologia seguem influenciando o debate ambiental, de forma que mesmo a "politização da ecologia" dá-se mediada por um viés naturalista, tecnicista ou do romantismo ingênuo (Loureiro, 2002). ${ }^{5}$ O discurso ecológico, ainda quando formula a crítica ao produtivismo, não o apreende como lógica intrínseca ao modo capitalista de produzir. Ao separar capitalismo e produtivismo, deixa de agarrar as determinações da questão ambiental e promove o fetiche da possibilidade de edificação de uma sociedade de "capitalismo limpo". Essas formulações desbordam para o campo da política, promovendo o

3. Art. 196 da Constituição Federal.

4. O mapa dos conflitos envolvendo injustiça ambiental e saúde no Brasil (2013) registrou 297 casos, sendo que 202 referem-se aos povos ou comunidades tradicionais: indígenas, quilombolas, ribeirinhos, pescadores artesanais e/ou marisqueiras, entre outros.

5. Sem dúvida, "a grande contribuição da ecologia foi - e continua sendo - levar-nos a tomar consciência dos perigos que ameaçam o planeta" (Löwy, 2000, p. 233). 
desconhecimento das teias que vinculam "questão social" e "questão ambiental", assim como o papel protagonista do trabalho na superação de ambas.

Segundo Foladori (2002, p. 37),

A ecologia, ao tempo que oferece luz sobre a maneira de analisar o entorno, também conduz a pensar no comportamento da sociedade humana como se fosse o de um formigueiro, sem advertir-se que a sociedade humana difere do resto dos seres vivos em sua relação com o ambiente externo. A divisão social do trabalho e a distribuição da riqueza material são duas características determinadas social e historicamente, são precondições, e regulam o comportamento do ser humano com a natureza externa. Isto não sucede em nenhuma outra espécie de seres vivos, donde o comportamento com a natureza externa está regulado geneticamente e donde cada geração parte do zero. Na sociedade humana as relações sociais de produção determinam a relação com a natureza externa. ${ }^{6}$

A trilha metodológica adotada neste trabalho se encaminha no sentido de situar o debate sobre a relação entre ambiente e saúde no leito das relações sociais de classe que se constituem no Brasil no tempo presente, buscando identificar as principais mediações que vinculam esse universo temático à dinâmica do processo de acumulação capitalista.

Em face das mencionadas antecipações metodológicas e sem que se pretenda abarcar a complexidade do tema, procede esclarecer que o objetivo deste artigo é problematizar as principais contradições do modelo de desenvolvimento brasileiro, sob a hegemonia ideopolítica do chamado neodesenvolvimentismo, enfocando a relação ambiente e saúde e suas principais manifestações no contexto político atual.

Demonstrar-se-á que a vulgata oficial acerca do desenvolvimento abarca um discurso de sustentabilidade, de preocupação socioambiental, porém esse discurso não ganha efetividade, posto que o modelo de desenvolvimento em curso reitera a inserção subalterna e periférica do país na Divisão Internacional do Trabalho, acentuando a quebra de conquistas econômico-sociais e ambientais anteriores. Advoga-se que em nome da sustentabilidade econômica promove-se uma insustentabilidade socioambiental, com fortes rebatimentos sobre as condições de saúde da população. A proposição, aqui, é oferecer contribuições e observações

6. Tradução nossa. 
embrionárias, cujo fim último é desvelar as contradições que se põem na atual conjuntura e a ideologia que lhe dá suporte, as quais manifestam o próprio modo de ser burguês.

\section{Ambiente e saúde no "neodesenvolvimentismo": a face inequívoca da insustentabilidade socioambiental}

O processo de "mundialização do capital" (Chesnais, 2005) é marcado pela hegemonia do capital financeiro. $\mathrm{O}$ traço distintivo do momento presente reside, pois, no fato de que, ancorado nas novas tecnologias, o capital rentista assume hegemonia na sociedade, definindo novas bases do processo de acumulação. Por sua vez, Harvey (2004) denominou esse movimento de "acumulação por espoliação", a qual se assenta na criação de novos mecanismos de valorização de capitais: a) a ênfase nos direitos de propriedade intelectual e a biopirataria em favor das grandes corporações; b) a mercantilização das formas culturais e simbólicas de expressão humana, com a exploração da cultura, sobretudo das comunidades locais; c) a mercantilização dos recursos ambientais globais, como a água, o ar e o subsolo; d) as privatizações dos bens públicos, entre outros.

Do ponto de vista ambiental, o aprofundamento da subalternidade das economias periféricas na divisão internacional do trabalho como parte do capital mundializado deriva da exploração dos recursos naturais e de uma força de trabalho mal remunerada e farta, além de uma legislação ambiental pouco rigorosa e uma regulação ambiental pública flexível. Sob pressão das grandes corporações verifica-se uma redefinição da divisão internacional dos custos ambientais, a qual redimensiona o papel do mercado, subsume os Estados nacionais e centra a discussão nos problemas ambientais tidos como "globais" - o aquecimento planetário, a perda da biodiversidade etc. de interesse dos países centrais - , enquanto os impactos das transnacionais na periferia são desconsiderados, a exemplo do lixo tóxico, dos efeitos dos agrotóxicos, a contaminação dos fluxos d'água, entre tantos (Foladori, 2002).

Na última década, a inserção brasileira na mundialização financeira ocorre mediante a implementação de um modelo de desenvolvimento, o chamado neodesenvolvimentismo. Tal modelo baseia-se na articulação entre a exportação de produtos primários (agrário-extrativistas) e na realização de grandes obras de infraestrutura - especialmente aquelas afetas à organização dos eventos e à produção 
de energia -, além do fomento ao mercado interno, baseado em bens de consumo duráveis, produzidos em larga medida pelos monopólios.

Para sua legitimidade conta, além da estabilidade econômica, com alguns avanços na área social, a exemplo da recomposição do poder de compra do salário mínimo, o incremento da oferta de crédito (o que permitiu a expansão do consumo para segmentos importantes da classe trabalhadora, ironicamente denominada de "nova classe média”) e a expansão dos programas sociais (Bolsa-Família, Pronaf etc.).

Nesse modelo de desenvolvimento, caucionado em grandes projetos voltados para a expansão do capital no território nacional, com forte apoio do aparato estatal e uso intensivo de recursos naturais, a dimensão ambiental é largamente subsumida aos interesses dos grandes agrupamentos econômicos — apesar da propalada sustentabilidade -, o que tende a acentuar os conflitos socioambientais, tanto no campo quanto nas cidades (Silva e Araújo, 2013).

Maricato (2013) ilustra bem esse movimento

Com a globalização, o território brasileiro passa por notável transformação. Mudam as dinâmicas demográfica, urbana e ambiental, além das social e econômica. A exportação de commodities - grãos, carnes, celulose, etanol, minérios — ganha o centro da política econômica e sua produção reorienta os processos demográficos. A urbanização se interioriza. $\mathrm{O}$ tsunami dos capitais globais e nacionais passou antes pelo campo, subordinando o que encontrou pela frente: terras indígenas ou de quilombolas, florestas amplamente derrubadas, o MST criminalizado, e lideranças, inclusive religiosas, assassinadas.

No campo, os impactos negativos decorrentes da inserção internacional fortemente calcada no fornecimento de commodities, ainda que nem sempre tenham sido mensurados, são largamente conhecidos. A perda da biodiversidade, o uso intensivo de agrotóxicos, a concentração fundiária - com duro ataque aos direitos dos povos indígenas e quilombolas -, os desmatamentos, a biopirataria, o aumento da poluição de rios e mares, o saque aos recursos naturais continuam sendo sistematicamente denunciados, principalmente pelos movimentos sociais ligados ao campo. ${ }^{7}$

7. Sobre os impactos dessas atividades afirma o Ipea: "A maior parte dos artigos econômicos sobre o tema foca-se em poluição industrial, associada à poluição urbana e em alguns tipos de poluentes para os quais 
A ofensiva do capital no campo se assenta em uma estrutura de classes arcaica e conservadora, erguida sobre o latifúndio - e a histórica concentração de riqueza e de poder que lhe é imanente - , e a ultrapassa. O agronegócio no comando da acumulação no campo configura um subsistema técnico e político que envolve o capital financeiro, a indústria química, a indústria de biotecnologia, sementes, fertilizantes, tratores, enfim, toda a indústria metal-mecânica, constituindo um modelo agrícola e pecuário que vincula a agricultura químico-dependente e os monocultivos para a exportação, o qual vem sendo incorporado, financiado e apoiado pelo Estado brasileiro (Rigotto, 2010).

A exposição das populações aos agrotóxicos é múltipla e diversa e se tornou emblemática dos danos ambientais, especificamente à saúde. ${ }^{8} \mathrm{O}$ Brasil tornou-se, desde 2008, o maior consumidor mundial de agrotóxicos, sendo que os segmentos atingidos vão desde os trabalhadores das empresas, os quais manipulam e aplicam os venenos, os pequenos produtores que por vezes são engolfados no discurso de parceria com o agronegócio, os moradores dessas regiões e os consumidores de alimentos contaminados. ${ }^{9}$

Mas, além dos efeitos mais sentidos e debatidos o que se constata é o exaurimento dos ecossistemas, a perda progressiva das características e potencialidades ambientais que o processo de mercantilização da natureza vai transformando-a em "mero suporte" para a acumulação de capitais. Afinal, exportar commodities implica exportar água, solo, exportando também, muitas vezes, a saúde de vidas humanas. "Estão em risco a fertilidade dos solos, das águas, a diversidade biológica

há mais disponibilidade de dados e são mais comparáveis em estudos entre indústrias ou entre países. Logo, esses estudos são incapazes de capturar problemas socioambientais locais específicos a algumas atividades produtivas, especialmente nas áreas rurais, como no caso da soja ou da mineração no Brasil” (2011, p. 5).

8. O aumento na utilização desses venenos no Brasil reflete no crescimento do número de intoxicações agudas por agrotóxicos registradas pelo Sistema de Informação de Agravos de Notificação (Sinan) do Ministério da Saúde (MS): de 2.071 notificações em 2007, esse número passou para 3.466 em 2011, um aumento de $67,3 \%$. Já o Sistema Nacional de Informações Tóxico-Farmacológicas (Sinitox) registrou, no ano de 2009, 5.253 casos de intoxicação por agrotóxicos de uso agrícola, um total de 188 óbitos por esses quatro tipos de intoxicações registradas (Antunes, 2013).

9. Pesquisas realizadas pela Agência Nacional de Vigilância Sanitária (Anvisa, 2011) em Lucas do Rio Verde (MS) identificaram resíduos de agrotóxicos em $83 \%$ dos poços de água potável das escolas, em $56 \%$ das amostras de chuva e em $25 \%$ das amostras de ar, além da presença de resíduos de agrotóxicos no leite materno. "Os resultados podem ser oriundos da exposição ocupacional, ambiental e alimentar do processo produtivo da agricultura que expôs a população a 136 litros de agrotóxico por habitante na safra agrícola de 2010" (Antunes, 2013). 
e genética, o clima e, com isso, a segurança alimentar e nutricional. A única estratégia para o capital parece ser a corrida tecnológica e uma crescente artificialização do planeta e da vida humana" (Leroy e Meireles, 2013, p. 117).

Nas cidades, o complexo jogo de interesses subjacente a essa dinâmica regressiva revela a forte presença das grandes empreiteiras envolvidas com os projetos de infraestrutura, dos bancos de financiamento e da indústria automobilística, além de setores da burocracia estatal determinados a impulsionar o crescimento econômico a todo custo, tanto como estratégia para assegurar os lucros capitalistas em tempo de crise mundial quanto para garantir o fortalecimento do bloco político no poder.

Seguindo as pegadas do processo de urbanização brasileira, caracterizado pela contínua concentração de terra, o atual modelo de desenvolvimento segue expulsando pessoas das áreas rurais, fazendo com que as cidades tornem-se cada vez mais insustentáveis, dada a disparidade crescente entre aumento populacional e baixa qualidade dos serviços públicos e de infraestrutura, além da concentração do solo urbano.

Ao tempo em que impulsiona a geração de empregos, os atuais investimentos em infraestrutura urbana, contraditória e dialeticamente, vêm produzindo um conjunto de novas problemáticas, constituindo o que Vainer (2013) denominou "cidade-mercadoria". Trata-se de uma mercadoria especial "de luxo", na qual ocorre a "transfiguração da pobreza", visto que esta passa a ser o entorno, o ambiente: a cidade é uma mercadoria de luxo, a ser consumida por um público específico, exigente e qualificado, "destinada a um grupo de elite, de potenciais compradores: o capital internacional, visitantes e usuários solváveis". ${ }^{10}$

Resulta desse movimento a alta dos preços dos imóveis (acirrando a especulação imobiliária e a consequente intensificação das disputas pela terra), além da expulsão dos pobres para a "periferia da periferia” (Maricato, 2013), restando-lhes ocupar áreas de proteção ambiental ou mesmo áreas de risco. Retomam-se os despejos violentos, e as comunidades localizadas em regiões cobiçadas pelo mercado não raro são alvo de incêndios, nunca devidamente esclarecidos e dos quais os próprios moradores são quase sempre culpabilizados.

10. Disponível em: <http://unuhospedagem.com.br/revista/rbeur/index.php/anais/article/viewFile/1866/1833>. Acesso em: 22 jan. 2015. 
A reprodução de uma trajetória histórica de ocupação territorial segregacionista conduz os mais pobres para regiões marcadas pela precariedade (ou mesmo ausência) de serviços essenciais, sendo condenados a percorrer, diariamente, longas distâncias para chegar ao trabalho, para não falar da violência e do abandono de toda sorte a que estão submetidos. ${ }^{11}$

As evidências acima tratadas indicam que o chamado neodesenvolvimentismo vem impulsionando, tanto no campo quanto nas cidades, um amplo movimento de expansão de capitais, subjugando os trabalhadores rurais, urbanos e as populações tradicionais aos propósitos da acumulação privada.

Os impactos desse processo, tanto ambientais quanto sociais, especialmente na saúde humana, vêm sendo objeto de estudo de diversas áreas do conhecimento, invocando pesquisadores e intelectuais que não se renderam ao projeto hegemônico do capital. ${ }^{12}$

A tendência apontada por esses estudos indicam que as transformações no campo acarretam inúmeros impactos no meio urbano e vice-versa. Assim, a degradação ambiental decorrente do monocultivo, da mineração e das hidrelétricas está relacionada com a insegurança hídrica e química (produzida por uso de agrotóxicos), redução da biodiversidade e poluição, além dos efeitos controversos dos chamados agrocombustíveis (etanol, biodiesel etc.), de maneira que os impactos dessas atividades não se extinguem no locus de sua ocorrência, mas tendem a se projetar em maior escala.

Nesse sentido, ilustra Porto (2013, p. 139):

Ainda que os fluxos migratórios campo-cidade tenham se reduzido bastante com relação às décadas anteriores, a expansão dos monocultivos da cana, da soja e a própria agropecuária continuam gerando dinâmicas extremamente perversas para as populações rurais em várias regiões do país, com impactos nas regiões urbanas relacionados à formação das desigualdades sociais que marcam periferias e favelas nas cidades. Continua a existir, portanto, uma forte interdependência ente as dinâmicas urbanas e rurais.

11. No Brasil, entre a faixa etária de 19 e 26 anos, as taxas de mortalidade violenta ultrapassam os cem óbitos por 100 mil jovens. A partir de dez homicídios por 100 mil habitantes, considera-se uma epidemia. No caso do Brasil, onde há cem homicídios para cada 100 mil habitantes, significa que tem dez vezes uma situação epidêmica (Waselfisz, 2014).

12. Os estudos que resultaram na publicação Injustiça ambiental e saúde no Brasil: o mapa de conflitos (Porto, Pacheco e Leroy, 2013) é uma feliz expressão dessas iniciativas. 
Ao analisar as principais razões para os conflitos urbanos, Porto elenca um conjunto de fatores relacionados com os impactos do modelo de desenvolvimento nas cidades, entre eles:

a) Os efeitos das indústrias perigosas e poluentes que afetam as populações que habitam seus entornos. São, em geral, indústrias químicas, petroquímicas, siderúrgicas, dentre outras, localizadas em áreas densas ou que atraem as populações após sua instalação. A omissão do Estado, seja no tocante à garantia do cumprimento das condicionalidades de licenciamento ambiental, seja pela ausência de planejamento urbano, acaba por expor a população a problemas de saúde e de contaminação do solo e/ou do ar, afetando principalmente crianças e idosos.

b) A contaminação por lixo industrial tóxico ou pelo lixo urbano. O complexo problema do lixo no Brasil envolve uma cadeia de omissões e descasos que vai desde a deposição inadequada (em lixões), realizada em sua quase totalidade pelos poderes municipais, à superexploração dos trabalhadores da catação (pela indústria de reciclagem via deposeiros, com a conivência do poder público), até a desresponsabilização dos municípios e estados com os impactos ambientais dos lixões, sobretudo para os que moram e/ou neles trabalham (crianças e adultos) em condições profundamente insalubres. ${ }^{13}$ Com relação ao lixo tóxico, inúmeros são os exemplos que se proliferam pelo país, contaminando o ambiente e afetando a saúde da população. ${ }^{14}$

c) Os desastres decorrentes dos eventos climáticos extremos (chuvas torrenciais, enxurradas, enchentes etc.) que tendem a afetar as populações pobres, localizadas em áreas de risco. As mudanças climáticas tendem a tornar os eventos naturais mais rigorosos, afetando, assim, os mais expostos. Deve-se destacar que após esses eventos a população tem que enfrentar várias moléstias resultantes da exposição aos vetores, a exemplo de verminoses, leptospirose etc.

13. A despeito de a Política Nacional de Resíduos Sólidos — PNRS (2010) haver estabelecido prazo-limite de quatro anos para o fechamento dos lixões, o fato é que a maior parte dos municípios brasileiros não a cumpriu e os gestores alegam dificuldades orçamentárias e políticas para fazê-lo.

14. Caso emblemático é a Shell, envolvida em grave contaminação do lençol freático nas proximidades do rio Atibaia em Paulínia (SP). Em 2001, 156 pessoas estavam contaminadas, 86\% dos moradores do bairro. Destas, $88 \%$ apresentavam intoxicação crônica, incluindo tumores hepáticos e da tireoide (Porto, 2013). 
d) A falta de saneamento básico integra uma cadeia de omissões e destratos em relação à conservação dos recursos hídricos em todo o país. Ante a precariedade ou ausência dos serviços, cabe à população improvisar, o que em geral acaba contaminando os mananciais de onde a população se nutre. ${ }^{15}$

Cabe enfatizar que os elementos acima referidos, como partes da dinâmica contraditória das cidades brasileiras, encontram-se, na atualidade, mediados pela profunda e excludente concentração do solo urbano. Conforme indicamos, o pacto entre as grandes incorporadoras do setor da construção civil, o setor bancário e os segmentos envolvidos com a gestão cidades direcionam os processos de expansão urbana em função dos interesses do mercado imobiliário e do grande capital. Nesse sentido, os investimentos públicos acabam por constituir novos polos de valorização mercantil, alimentando o círculo vicioso da especulação imobiliária, com a expulsão dos pobres para as franjas das cidades e a consequente negação do direito à moradia.

As problemáticas acima tratadas refletem diretamente no quadro de saúde da população. Nele se imbricam os tradicionais problemas de saúde, reproduzidos ao longo de décadas, com as novas doenças e agravos decorrentes das mudanças de hábitos, de estilos de vida, alimentação e moradia, entre outros, agravados pelas novas problemáticas decorrentes das intensas modificações na dinâmica societária recente e dos avanços do capital sobre o território. "O Brasil é considerado um retrato da acumulação epidemiológica, em que mais de $50 \%$ da mortalidade, atualmente, deve-se a doenças do aparelho circulatório e a causas externas. [...] permanecem as doenças infecciosas e desnutrição, ressurgem a dengue e o cólera e crescem os casos de Aids" (Souza e Andrade, 2014, p. 15).

Para que se possam abarcar as complexas mediações que envolvem a questão da saúde, há que se ter em conta as particularidades sócio-históricas do país, sua desigualdade estrutural, a concentração de renda e de poder e os indicadores sociais alarmantes.

15. Estudo do Programa para o Meio Ambiente das Nações Unidas - PNMA afirma que pelo menos 1,8 bilhão de crianças com menos de cinco anos de idade morrem por ano, no mundo, em decorrência da "água doente", o que representa uma morte a cada vinte segundos. O consumo e o uso de água não tratada e poluída matam mais do que todas as formas de violência (Giraldi, 2010). 
Nestes termos, refere-se Coutinho (2009, p.168):

Em países onde ainda persistem grandes desigualdades sociais e regionais, como é o nosso caso, observa-se que o perfil de morbi-mortalidade apresenta características daquele encontrado nos países capitalistas avançados, com doenças e agravos à saúde como streess, cânceres, doenças cardiovasculares, isto é, as doenças degenerativas, além de lesões e mortes decorrentes de causas externas (acidentes de trabalho, acidentes de trânsito, homicídios, doenças correlacionadas à poluição, doenças vinculadas à precarização do trabalho, tais como lesão por esforços repetitivos, cânceres ocupacionais, contaminações químicas, perda auditiva induzida por ruído etc.). Ao mesmo tempo, contudo, persistem e, nas últimas décadas, reaparecem e recrudescem as doenças que tipificam a pobreza e a miséria, a falta de saneamento básico, a má nutrição, ou seja, doenças infecciosas e parasitárias próprias das péssimas condições de vida da maioria da população.

Estudos desenvolvidos pela Fiocruz no âmbito do Mapa de Conflitos (2013) elencam três ordens de agravos e danos à saúde em áreas de conflitos socioambientais: a violência, a insegurança alimentar e nutricional e a perda da qualidade de vida. A violência é tomada, no referido estudo, em suas múltiplas expressões, as quais articulam a saúde ao campo dos direitos humanos e à luta por democracia. As ameaças, a coação física, assassinatos, lesão corporal são algumas das queixas mais frequentes entre os atingidos. A insegurança alimentar é apontada como resultante da interdição das comunidades de produzirem, comercializarem e consumirem seus alimentos em conformidade com sua cultura e seu modo de vida. Destaque-se, ainda, a existência de doenças crônicas decorrentes da exposição a poluentes diversos, a exemplo de substâncias químicas de indústrias ou depósitos de resíduos, além dos agrotóxicos. ${ }^{16}$ No tocante à perda da qualidade de vida os estudos apontam que elementos essenciais para a reprodução da vida nos territórios em conflito estão sendo impactados: a relação com a natureza, o uso dos recursos

16. Os agrotóxicos são um exemplo dessas alterações no modo de vida das populações. Para Rigotto (2010), não existe agrotóxico que não seja tóxico. Portanto, não há nenhum que não apresente risco à saúde humana mediante exposição e posterior contaminação. Os agrotóxicos provocam dois tipos de efeitos: os agudos, provocados nas horas seguintes à exposição; e os crônicos, que podem se manifestar em meses, anos e até décadas. [...] Os efeitos de resíduos de agrotóxicos no nosso organismo podem manifestar complicações, como alterações genéticas, problemas neurotóxicos, má-formação fetal, abortos, efeitos teratogênicos, desregulação hormonal, desenvolvimento de células cancerígenas. 
naturais, a cultura e o modo de vida das comunidades, tudo em nome do progresso e do crescimento econômico em benefício de todos (Pacheco, Porto e Rocha, 2013). Assim,

No que se refere aos efeitos dos conflitos ambientais sobre a saúde das populações, poderíamos aumentar bastante a lista de diferentes agravos que recaem sobre elas se considerássemos o nível de tensão e estresse, especialmente entre os mais velhos e as lideranças que estão nas frentes de luta de defesa dos territórios. A ameaça direta ou a perda da terra, dos modos de vida e tradições, assim como outras ações de fundo claramente preconceituoso e racista, são elementos que atingem diretamente a saúde dessas populações. São emblemáticos o já mencionado nível elevado de suicídio entre os povos indígenas e o agravo das doenças nervosas que, como aparente causa de morte natural, está fortemente vinculada às tensões vivenciadas pelas populações ameaçadas ou pelo alto nível de perdas que acompanham esses conflitos. (Pacheco e Faustino, 2013, p. 109)

De resto, vale destacar que o conjunto desses elementos ganha maior relevo na medida em que as populações pobres se deparam com a precariedade dos serviços de saúde, o que se torna mais dramático quando se trata dos habitantes das áreas rurais, onde esses serviços são ainda mais escassos, o que implica longos deslocamentos para obter o acesso aos mesmos.

Esse contexto impõe imensos desafios para a política de saúde na atualidade. Esta, como as demais políticas constitutivas da seguridade social - previdência e assistência social - vem sofrendo os constrangimentos derivados do processo de contrarreforma do Estado brasileiro, com forte incidência sobre a qualidade dos serviços prestados pelo Sistema Único de Saúde - SUS. Esse movimento se manifesta através da institucionalização de pactos, planos de desenvolvimento e um amplo projeto de privatização da saúde, através das fundações estatais de direito privado, as quais se apresentam como portadoras do ideário da Reforma Sanitária (Soares, 2012). A constituição da Empresa Brasileira de Serviços Hospitalares EBSERH representa mais um passo nessa trajetória de avanço da privatização do SUS, com rebatimentos na pesquisa e na formação de quadros para o setor, já que estão sob seu comando cerca de metade dos hospitais universitários federais. E seguem as pressões para novas adesões.

Contraditória e dialeticamente, a contrarreforma na saúde vem se dando a despeito da manutenção e de avanços no arcabouço jurídico-formal da área e nos 
arranjos institucionais delineados desde a Constituição federal de 1988. Desde então, ampliou-se a consciência de que a saúde, individual e coletiva, e as suas dimensões físicas e mentais, estão intrinsecamente relacionadas à qualidade do meio ambiente (Minayo, 2006), o que permitiu a organização de um campo da saúde pública — a saúde ambiental — voltado para o estudo e a intervenção nos fatores intervenientes da relação ambiente e saúde. ${ }^{17}$

Nesses termos, a saúde ambiental como uma área do conhecimento, subsidiária à produção de políticas públicas e de intervenção, constitui um importante avanço, já que invoca a necessária efetivação dos princípios do SUS no sentido da realização de ações efetivas voltadas para a melhoria da qualidade de vida da população. Por outro lado, o que se evidencia na realidade atual é que os rumos da política de saúde encontram-se em conformidade com o atual modelo de desenvolvimento e a lógica que o preside: a necessidade de alargamento dos espaços de valorização do capital para atender aos interesses das corporações mercantis acaba confinando a política pública e submetendo-a aos desígnios da acumulação.

Segundo Soares (2012, p. 99)

A política de saúde, dessa forma, compõe esse modelo de desenvolvimento, seja estimulando o financiamento da indústria nacional (produtores públicos e privados), seja criando as condições para expansão da saúde suplementar, seja possibilitando que na própria expansão do SUS esteja garantida também a ampliação do mercado privado, através das diversas modalidades de Parceria-Público-Privado (PPP), tão características do PAC. As PPPs constituem-se uma estratégia mundial de maximização do capital implementada por diversos estados, em meio às tendências de supercapitalização.

Atualmente, o marco contraditório da política de saúde indica que os avanços obtidos no arcabouço legal defrontam-se com uma tendência que lhe tensiona, o que tende a esvaziar as possibilidades de o sistema atender, efetivamente, às necessidades da população. Não restam dúvidas de que essas necessidades extrapolam

17. Saúde ambiental aborda os aspectos da saúde e qualidade de vida humana, determinados por fatores ambientais, sejam estes físicos, químicos, biológicos ou sociais. Refere-se também à teoria e à prática de avaliação, correção, controle e prevenção daqueles fatores que, presentes no ambiente, podem afetar potencialmente de forma adversa a saúde humana de gerações presentes ou futuras (OMS — Organização Mundial de Saúde, apud Tambellini e Câmara, 1998). 
as fronteiras da política de saúde por si mesma. A intersetorialidade ${ }^{18}$ é, no âmbito da política pública, um caminho ainda em construção, dadas as complexas barreiras culturais e operacionais com que se depara o que constitui, nesta conjuntura, mais um desafio de monta.

Assim como no âmbito da saúde, a agenda ambiental brasileira vem apontando retrocessos, tanto do ponto de vista de ações estruturadoras quanto regulatórias: a aprovação de um código florestal claramente regressivo; ${ }^{19}$ a aprovação da Medida Provisória n. 558, ${ }^{20}$ que reduz áreas de preservação na Amazônia, o congelamento dos processos de reconhecimento de terras indígenas e de quilombolas são alguns dos fenômenos mais ilustrativos dessa tendência.

A ofensiva do agronegócio não cessa, e a conjuntura pós-eleitoral tem favorecido a ação das corporações - e de seus intelectuais orgânicos na burocracia estatal - no sentido de fazer retroceder a legislação nesse campo, atentando, inclusive, contra o direito elementar à informação, como no caso dos transgênicos. ${ }^{21}$ Negar à população o acesso à informação sobre o que está comprando, sobretudo no que tange à alimentação, constitui um abuso que mesmo os mais arraigados defensores

18. Na saúde, a intersetorialidade é definida como [...] uma estratégia política complexa, cujo resultado na gestão de uma cidade é a superação da fragmentação das políticas nas várias áreas onde são executadas. Tem como desafio articular diferentes setores na resolução de problemas no cotidiano da gestão e torna-se estratégia para a garantia do direito à saúde. [...] Permite considerar o cidadão na sua totalidade, nas suas necessidades individuais e coletivas, demonstrando que ações resolutivas em saúde requerem necessariamente parcerias com outros setores como Educação, Trabalho e Emprego, Habitação, Cultura, Segurança, Alimentar e outros (Brasil, 2009, p. 194).

19. A alegação de caducidade da lei anterior em face das necessidades do desenvolvimento prestou-se, efetivamente, a encobrir a drástica redução das Áreas de Proteção Permanentes (APPs) - essenciais para a proteção dos mananciais -, o contrabando de milhões de imóveis rurais sob a alegada solidariedade aos "pequenos produtores" e a anistia aos desmatadores (anteriores a 2008).

20. A Medida Provisória n. 558/2012 altera os limites de unidades de conservação na Amazônia. As Unidades de Conservação (UCs) que terão seu tamanho modificado são o Parque Nacional da Amazônia, Parque Nacional dos Campos Amazônicos, Parque Nacional Mapinguari, Floresta Nacional de Itaituba I e II, Floresta Nacional do Crepori e Área de Proteção Ambiental do Tapajós. O objetivo das mudanças nos limites das áreas é atender aos interesses do Ministério de Minas e Energia para a construção do Complexo Hidrelétrico Tapajós e do Ministério dos Transportes, para a retomada das obras da polêmica BR-163, que liga Cuiabá (MT) a Santarém (PA) (Bragança e Miotto, 2012).

21. Trata-se de projeto aprovado na Câmara dos Deputados que exclui da Lei de Biossegurança a informação de que o alimento contém produtos geneticamente modificados acima de $1 \%$. Neste caso, a impressão do $\mathrm{T}$ (transgênicos) envolto em um triângulo amarelo se faz obrigatória. O projeto segue para o Senado federal para votação. 
dos transgênicos não podem explicar. Por que se quer negar esse direito? Se não há o que temer, por que impedir que as pessoas saibam o que estão consumindo?

Outra área de forte tensionamento com o agronegócio e as corporações ligadas à indústria da construção é o licenciamento ambiental. Vale destacar a tendência a que vêm sendo submetidos os Estudos de Impactos Ambientais (EIA) e os Relatórios de Impacto Ambiental (Rima), cujo manuseio e uso por parte das classes dominantes e do seu Estado revelam uma ofensiva daqueles no sentido de esvaziar seu papel de instrumento de controle, transformando-os em meio e argumento em favor do crescimento econômico, sob a hipótese que este desborda, invariavelmente, em desenvolvimento social. Esse movimento vem acompanhado de um proposital esvaziamento dos órgãos de controle (licenciamento e fiscalização), cuja estrutura não acompanha o incremento das demandas, o que acarreta dificuldades e atrasos no cumprimento dos processos. Isto tem servido de argumento para a sonhada transferência para os municípios das atribuições relativas ao licenciamento ambiental, o que o tornaria mais facilmente suscetível às pressões dos empresários e burocratas, muitos dos quais interessados na flexibilização dos processos de licenciamento ambiental, a fim de liberar obras com claros problemas ambientais e sociais.

O caminho argumentativo percorrido até aqui se encaminha no sentido de demonstrar que o atual modelo de desenvolvimento, impulsionado pelo Estado em nome do progresso e da socialização dos ganhos, tem se revelado essencialmente desigual e predatório. À crescente mercantilização da natureza e sua transformação em fator de produção - de fortes consequências socioambientais sobretudo para as comunidades e povos tradicionais - agrega-se a dinâmica privatista na condução das políticas sociais, o que agrava sobremaneira o trato com as manifestações da questão social, dentre as quais se destaca a saúde pública no Brasil.

\section{Considerações finais}

Para fins de sua reprodução, o capital necessita difundir e socializar ideologias e práticas que buscam tornar universal os seus interesses, tecendo politicamente a ideia de que é possível compatibilizar produção da riqueza com sustentabilidade social e ambiental (Mota e Silva, 2009). Assim, o que se constata, na atual conjuntura brasileira, é que a bravata do progresso e da melhoria de vida para todos não passa de uma peça ideológica, cujo objetivo é a obtenção de legitimidade social para as práticas predatórias, afastando, assim, os obstáculos à acumulação privada. 
Tem-se, desta forma, a privatização dos ganhos econômicos, enquanto os danos sociais e ambientais que daí resultam são, quase sempre, socializados, em especial com as populações locais atingidas.

Nesse contexto, o que se delineia nessa conjuntura regressiva é a necessidade de intensificação das lutas de resistência e a busca por alargar as condições de reprodução da vida: lutas contra o desemprego e a precarização do trabalho, contra a expropriação das terras pelo capital e pela melhoria da qualidade dos serviços sociais e de saúde, entre tantas. Os conflitos que se alastram em todo o território nacional manifestam essa tendência e indicam o caminho. Mas as lutas de resistência não estão fadadas ao confinamento, à solidariedade entre trabalhadores do campo e da cidade, entre os povos que atingidos revelam seu potencial contestatório e de negação da ordem burguesa e avançam, propositivamente, na construção de uma alternativa à sociabilidade do capital. Afinal, "ambiente é um termo ambíguo. Para o trabalhador, o 'ambiente' será visto em função das necessidades; para o capitalista, em função do lucro" (Biolat, 1977, p. 46). É a atualização da velha (e para alguns, caduca) luta de classes, e só a história dirá o desfecho dessa contenda.

Recebido em 26/5/2015 - Aprovado em 8/6/2015

\section{Referências bibliográficas}

ANTUNES, André. Conhecimento cientifico e popular na luta pela saúde, 2013. Disponível em: $<$ http://www.epsjv.fiocruz.br/index.php?Area=Noticia\&Num=729>. Acesso em: 20 maio 2014.

BIOLAT, G. Marxismo e meio ambiente. Lisboa: Seara Nova, 1977.

BRAGANÇA, Daniele; MIOTTO, Karina. Através de medida provisória, Dilma flexibiliza área de mais unidades de conservação, 2012. Disponível em: <http://www.oeco.com.br/>. Acesso em: 8 mar. 2012.

BRASIL. Ministério da Saúde. Portal da Saúde. O SUS de A a Z. 2009. Disponível em: http://portal.saude.gov.br/portal/arquivos/pdf/sus_3edicao_completo.pdf. Acesso em: 10 out. 2012.

CHESNAIS, F. A finança mundializada. São Paulo: Boitempo, 2005. 
COUTINHO, Ronaldo. Direito à saúde, meio ambiente e urbanização. In: AHMED. Flávio; COUTINHO, Ronaldo (Orgs.). Cidades sustentáveis no Brasil e sua tutela jurídica. Rio de Janeiro: Lumen Juris, 2009.

FOLADORI, Guilhermo. Contenidos metodológicos de la educación ambiental. Tópicos en Educación Ambiental, v. 4, n. 11, p. 33-48, 2002. Disponível em: <http://www.ambiente. gov.ar/infotecaea/descargas/foladori03.pdf>. Acesso em: 8 out. 2012.

GIRALDI, Renata. Água poluida mata mais do que todos os tipos de violência, alerta ONU, 2010. Disponível em: <http://www.memoria.ebc.com.br/agenciabrasil/noticia/2010-03-22/ agua-poluida-mata-mais-do-que-todos-os-tipos-de-violencia-alerta-onu>. Acesso em: 25 mar. 2010.

HARVEY, D. O novo imperialismo. São Paulo: Loyola, 2004.

IPEA. O comércio internacional e a sustentabilidade socioambiental no Brasil. Comunicados do Ipea, n. 79, fev. 2011. Disponível em: <http://www.ipea.gov.br>. Acesso em: 20 jul. 2012.

LEROY, Jean Pierre; MEIRELES, Jeovah. Povos indígenas e comunidades tradicionais: os visados territórios dos invisíveis. In: PORTO, Marcelo Firpo; PACHECO, Tânia; LEROY, Jean Pierre (Orgs.). Injustiça ambiental e saúde no Brasil: o mapa de conflitos. Rio de Janeiro: Fiocruz, 2013.

LOUREIRO, C. F. B. Ambientalismo e lutas sociais no Brasil. Libertas, Juiz de Fora, v. 2, n. I, jan./jun. 2002.

LÖWY, M. De Marx ao ecossocialismo. In: ; BENSAID, D. Marxismo, modernidade e utopia. São Paulo: Xamã, 2000.

MARICATO, Ermínia. É a questão urbana, estúpido!, 2013. Disponível em: <http://www. diplomatique.org.br/artigo.php?id=1465>. Acesso em: 10 set. 2013.

MINAYO, M. C. de S. Saúde e ambiente: uma relação necessária. In: CAMPOS, G. W. de S. et al. Tratado de saúde coletiva. Rio de Janeiro: Fiocruz, 2006.

MOTA, Ana Elizabete; SILVA, Maria das Graças. Questão ambiental e o contraditório discurso da sustentabilidade. Praia Vermelha, Rio de Janeiro, v. 19, n. 2, 2009.

PACHECO, Tânia; PORTO, Marcelo Firpo; ROCHA, Diogo. Metodologia e resultados do Mapa: uma síntese dos casos de injustiça ambiental e saúde no Brasil. In: PORTO, Marcelo Firpo; PACHECO, Tânia; LEROY, Jean Pierre (Orgs.). Injustiça ambiental e saúde no Brasil: o mapa de conflitos. Rio de Janeiro: Fiocruz, 2013.

; FAUSTINO, Cristiane. A iniludível e desumana prevalência do racismo ambiental nos conflitos do mapa. In: PORTO, Marcelo Firpo; PACHECO, Tânia; LEROY, Jean 
Pierre (Orgs.). Injustiça ambiental e saúde no Brasil: o mapa de conflitos. Rio de Janeiro: Fiocruz, 2013.

PORTO, Marcelo Firpo. Injustiça ambiental no campo e nas cidades: do agronegócio químico-dependente às zonas de sacrifício urbanas. In: PORTO, Marcelo Firpo; PACHECO, Tânia; LEROY, Jean Pierre (Orgs.). Injustiça ambiental e saúde no Brasil: o mapa de conflitos. Rio de Janeiro: Fiocruz, 2013.

; PACHECO, Tânia; LEROY, Jean Pierre. Apresentação. In: (Orgs.). Injustiça ambiental e saúde no Brasil: o mapa de conflitos. Rio de Janeiro: Fiocruz, 2013. RIBEIRO, Helena. Saúde pública e meio ambiente: evolução do conhecimento e da prática, alguns aspectos éticos. Saúde e Sociedade, São Paulo, v. 13, n. 1, p. 70-80, jan./abr. 2004. Disponível em: <http://www.scielo.br/pdf/sausoc/v13n1/08.pdf>. Acesso em: 20 set. 2014.

RIGOTTO, Raquel. O uso seguro de agrotóxicos é um mito. Entrevista realizada por Leila Leal em 22/09/2010. Disponível em: <http://www.epsjv.fiocruz.br/index.php?Area=Entrev ista $\&$ Num $=17 \&$ Destaques $>$. Acesso em: 15 out. 2010.

SILVA, Maria das Graças; ARAÚJO, Nailsa Maria Sousa. Neodesenvolvimentismo e sustentabilidade socioambiental no Brasil: duas faces da ideologia burguesa em tempos de crise do capital. In: COSTA, Gilmaisa M.; SOUZA, Reivan (Orgs.). O social em perspectiva: políticas, trabalho, Serviço Social. 1. ed. Maceió: Edufal, 2013. v. 1, p. 191-212.

SOARES, Raquel Cavalcante. A racionalidade da contrarreforma na política de saúde e o Serviço Social. In: BRAVO, Maria Inês de Souza; MENEZES, Juliana Souza Bravo (Orgs.). Saúde, Serviço Social, movimentos sociais e conselhos: desafios atuais. São Paulo: Cortez, 2012.

SOUZA, Cinoélia Leal; ANDRADE, Cristina Setenta. Saúde, meio ambiente e território: uma discussão necessária na formação em saúde. Ciência \& Saúde Coletiva, Rio de Janeiro, v. 19, n. 10, out. 2014. Disponível em: <http://www.dx.doi.org/10.1590/1413812320141910.08992014>. Acesso em: 10 mar. 2015.

TAMBELLINI, Anamaria Testa; CÂMARA, Volney de Magalhães. A temática saúde e ambiente no processo de desenvolvimento do campo da saúde coletiva: aspectos históricos, conceituais e metodológicos. Ciência e Saúde Coletiva. 3 (2): 47-59, 1998. Disponível em: http://www.scielosp.org/pdf/csc/v3n2/7150.pdf. Acesso em: 2 fev. 2015.

VAINER, Carlos. Pátria, empresa e mercadoria. Notas sobre a estratégia discursiva do planejamento estratégico urbano. 2013. Disponível em: <http://www.unuhospedagem.com. br/revista/rbeur/index.php/anais/article/viewFile/1866/1833>. Acesso em: 10 jan. 2015.

WASELFISZ, J. Mapa da violência 2014 confirma caso de violência epidêmica no Brasil. Disponível em: <http://www.ecodebate.com.br/2014/07/15/>. Acesso em: 20 jul. 2014. 